\title{
Chapter
}

2

\section{SCRATCH FOR ARDUINO: Desenvolvendo o pensamento computacional com auxílio da robótica educacional}

\author{
Alan Gomes Silva, Ramásio Ferreira de Melo, Rogério Pereira de Sousa, \\ Charles França de Sousa, Elielton Pereira de Santana, Karoline Araújo \\ Nascimento, Jaciara Costa Naziozeno.
}

\begin{abstract}
The aim of this short course is to make a didactic model with Arduino and related for the development of computational thinking and introductory learning to computer programming. The course will be offered in 4 hours for 15 participants and divided into teams. It is expected that the activity will promote enthusiasm in the participants and can contribute to the significant development of Arduino and programming logic concepts and skills, in order to introduce them into computational thinking with the aid of educational robotics allowing greater concreteness and autonomy of students, preparing them for the challenges of learning and living in today's society.
\end{abstract}

\section{Resumo}

O objetivo deste minicurso é a confecção de um modelo didático com Arduino e afins para o desenvolvimento do pensamento computacional e aprendizado introdutório a programação de computadores. O curso será ofertado em 4 horas de duração destinado a 15 participantes sendo divididos em equipes. Espera-se que a atividade promova entusiasmo nos participantes e possa contribuir para o desenvolvimento significativo de conceitos e habilidades de lógica de programação e Arduino, de forma a introduzi-los no pensamento computacional com auxílio da robótica educacional permitindo maior concretude e autonomia dos alunos, preparando-os para os desafios de aprender e viver na sociedade atual. 


\subsection{Introdução}

Papert Seymour considerado uma referência sobre o uso de computadores na Educação desenvolveu a Linguagem Logo que possibilitou a aplicação da Informática na Educação, defendendo sobre como uma ideia pode habitar uma mente jovem e as influências do computador nessa perspectiva (PAPERT, 1980).

O uso das Tecnologias Digitais de Informação e Comunicação (TDIC) na Educação Básica é abordado de diversas maneiras com o intuito de instigar o letramento digital, inclusão da disciplina no currículo e permitir explorar conceitos do Pensamento Computacional (PC) em jogos e robótica de maneira transversal (VALENTE, 2016).

O PC é um modo de pensar nas formulações de problemas e suas soluções, que devem ser representadas de forma generalizada e executadas por agentes de processamentos distintos (CUNY; SNYDER; WING, 2010). O PC tem como base a busca por maneiras alternativas para resolver problemas reais, compreender $\mathrm{o}$ comportamento humano e projetar sistemas embasando-se nos conceitos da Ciência da Computação (WING, 2006).

São princípios norteadores do PC definidos pelas organizações International Society for Technology in Education (ISTE) e America Computer Science Teachers Association (CSTA): coleta de dados, análise de dados, representação de dados, decomposição de problema, abstração, algoritmos, automação, paralelização e simulação (VALENTE, 2016).

Além disso, integrar o PC e algoritmos nas escolas pode contribuir para que os alunos adquiram habilidades e competências fundamentais para o convívio em uma sociedade tecnológica e globalizada (Brasil, 2012). Ainda pouco explorado na educação básica pública brasileira, o PC pode ser uma excelente abordagem para desenvolvimento lógico matemático.

Geralmente, as ações de integração das tecnologias nas escolas são voltadas para informática básica e utilização dos softwares de escritório. Os conhecimentos adquiridos por meio destes tipos de integração são defasados para a sociedade contemporânea, de modo a limitar o crescimento cognitivo do indivíduo com base na teoria do construcionismo de Papert (VALENTE, 2016; ARANTES; RIBEIRO, 2017).

Há trabalhos sobre o uso da ferramenta Scratch para o desenvolvimento do PC dentre eles estão (França; Amaral, 2013; Ramos; Teixeira, 2015; Rodriguez et al., 2015), sua utilização proporciona fácil manuseio por pessoas iniciantes na programação de maneira a substituir as linhas de código por blocos, porém, o uso do Scratch for Arduino (S4A) vai além, por permitir a prototipagem e desenvolvimento de projetos na plataforma Arduino a partir da interação do aluno em tempo real com dispositivo físico (KALIL et al., 2013).

O Scratch For Arduino (S4A) foi desenvolvido no Citilab pelo Edutec Research Group, com a ajuda do grupo de programação Smalltalk.cat e de colaboradores como Jorge Gómez e atualmente está na versão 1.3 (S4A, 2019). Oriundo do Scratch, o S4A é um ambiente para se programar de forma simplificada a plataforma Arduino. Sua interface é similar à do Scratch, exceto por adicionar blocos de ações para gerenciamento de sensores e atuadores (Figura 1). 
O S4A viabiliza a interação com a plataforma Arduino e permite maior usabilidade, substituindo sua IDE padrão baseada em Processing. Arduino é uma plataforma de prototipação, sendo uma placa física de distribuição livre. Permite conectar diversos sensores e atuadores como por exemplo, sensor de temperatura, luminosidade, umidade, distância e outros como LED, motores, Bluetooth, etc. (KALIL et al., 2013; ARDUINO, 2019).

O objetivo deste minicurso é a confecção de um modelo didático com Arduino e afins para o desenvolvimento do $\mathrm{PC}$ e aprendizado introdutório a programação de computadores.

Este capítulo está estruturado da seguinte forma: na Seção 2 os trabalhos que apresentam-se similares a este; na Seção 3 aborda sua relevância, na Seção 4 relata-se de forma detalhada as ações para a realização do minicurso; a Seção 5 traz os resultados esperados de forma a esclarecer o que os benefícios do minicurso; e por fim, os agradecimentos.

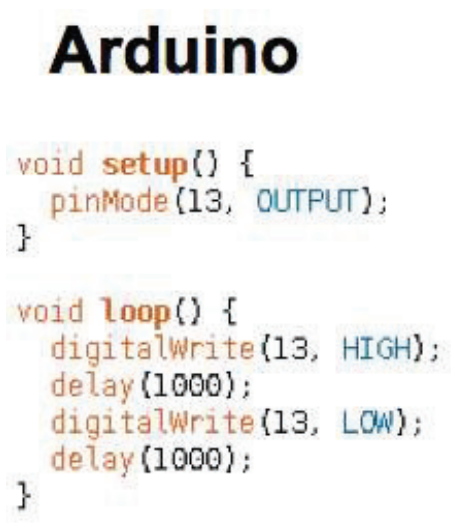$$
\text { Arduino }
$$

S4A

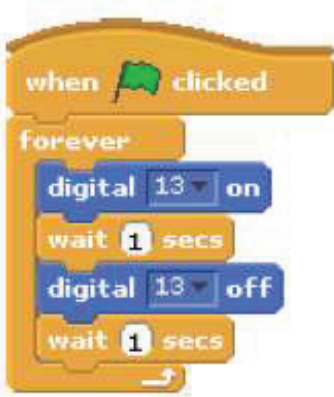

Figura 1: Comparativo entre códigos para piscar um LED, no Arduino e no S4A. Fonte: Página do arduineando 2019.

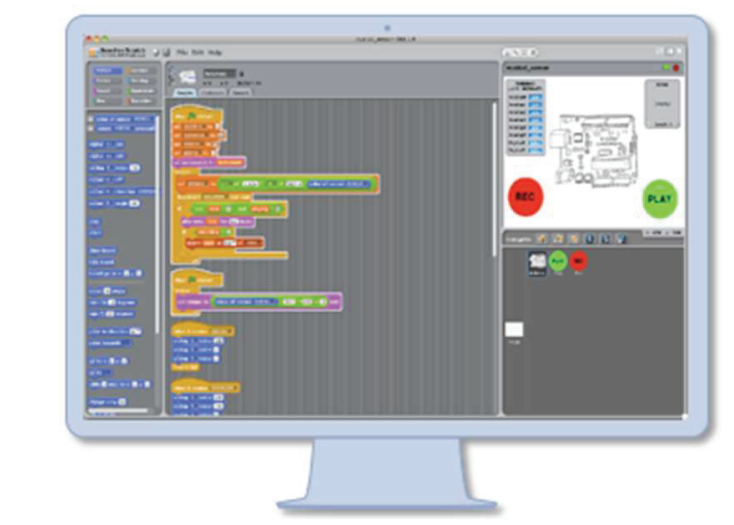

Figure 2: Interface completa, simples e intuitiva.

\subsection{Trabalhos Relacionados}

Serão abordados nesta seção, trabalhos e autores que de alguma forma contribuíram para o amadurecimento desta proposta de minicurso elencando os casos de sucesso e insucesso de experiências semelhantes. 
Kalil et al. (2013), relatam uma experiência sobre a robótica educacional no ensino médio analisando quais ferramentas se apresentam mais adequada para desenvolver a lógica e compreensão do mundo real: Arduino, S4A e Lego. Eles ressaltam a importância do ensino e aprendizagem de programação para que a sociedade esteja mais inserida ao universo da computação. Conclusivamente, apresentam o S4A como ferramenta mais adequada, devido sua interface, sintaxe, opção de escolha de idioma e baixo custo.

Sobreira, Takinami e Santos (2013) abordam sobre a relevância de trabalhar com tecnologias no Ensino Fundamental, objetivando formar indivíduos participativos e atuantes no século XXI, dentre os vários meios e ferramentas utilizáveis, o S4A é apontado como o aspecto pertinente até mesmo por ser inclusivo possuindo vários meios sensoriais, como: música, animação, cores, imagens, etc. Os autores concretizam que a linguagem de programação scratch mostrou resultados pragmáticos por aprimorar habilidades em contato com as múltiplas linguagens. Dessa forma, favorecem a criticidade por parte dos alunos, além de criatividade, curiosidade e reflexão de forma construtiva resolvendo problemas que exijam soluções e posturas autônomas para seu desenvolvimento.

Zanetti e Oliveira (2015) propõem uma prática pedagógica com a inserção da robótica educacional e do PC para introdução do ensino de programação em um curso técnico de informática integrado ao ensino médio. Foi trabalhado com três conceitos de programação: entradas e saídas, estrutura condicional e de repetição, para desviar o robô de um obstáculo utilizando o S4A e componentes do Arduino. As resultâncias do trabalho mostram que a prática abordada torna um ambiente de aprendizagem menos abstrato para o aluno, que ele venha a ser mais ativo na construção do conhecimento e do raciocínio lógico.

Albuquerque et al. (2016) relatam um experimento com alunos do curso técnico em mecatrônica integrado ao ensino médio. Utilizou-se para o ensino de programação a plataforma Arduino e o PC, de modo que eles construíssem em duplas um projeto de eletrônica do seu cotidiano. Constatou-se que os alunos não tiveram grandes dificuldades em trabalhar com o Arduino, a não ser, devido ao idioma inglês, destaca-se que a metodologia do experimento é mais apropriada do que a metodologia tradicional por apresentar uma aprendizagem menos abstrata, e foi possível desenvolver o PC por relacionar um problema da vida real sendo resolvido pelos alunos por intermédio dos conceitos de programação e do Arduino.

Pereira e Franco (2018) associaram o Scratch ao Arduino para desenvolver o PC com alunos do $7^{\circ}, 8^{\circ}$ e $9^{\circ}$ ano do ensino fundamental. Eles abordaram conteúdos de introdução a programação como: hardware e software, lógica e algoritmo, utilizam o S4A para desenvolver projetos que foram apresentados em uma feira de ciências pelos alunos. Os resultados elencados demonstram que foi possível relacionar os conhecimentos abstratos aos concretos, com a verificação dos códigos agindo sobre o hardware e os desafios impostos aos alunos induzindo-os a realizarem buscas de soluções, assim, influenciando no modo de aprendizagem dos alunos e tornando PC mais aparente.

\subsection{Justificativa}

Inserir o PC na escola possibilita que o aluno desenvolva habilidades que contribuam para o melhoramento do raciocínio lógico e matemático, que permitem a solução de problemas 
de forma transversal nas mais diversas áreas do conhecimento (SCAICO, 2013; BRASIL, 2012), contribuindo para a formação de alunos mais críticos, não apenas meros consumidores de tecnologias, mas sim, produtores de soluções tecnológicas para problemas reais do cotidiano (SANTOS, 2016; SCOLARI, 2007).

Por meio das TDIC é possível realizar o desenvolvimento de conceitos relacionados ao PC, como exemplo, apresentar problemas e situações, analisando as contribuições da tecnologia e as possibilidades que ela nos permite (VALENTE, 2016).

Com isso, a utilização do software S4A possibilita boa interação e é de fácil manuseio para pessoas iniciantes na programação, de maneira a substituir as linhas de código por blocos, onde são organizados de maneira a formar instruções para o Arduino, ao invés de fazer a utilização da sua IDE convencional (KALIL et al., 2013). O S4A permite ainda que o aluno possa visualizar o funcionamento de seu código agindo no dispositivo físico, que no caso seria o Arduino.

Falar em PC na educação, imagina-se logo em computadores nas escolas. $\mathrm{O}$ desenvolvimento do PC ultrapassa esta ideia do uso prescrito do computador, especialmente pela utilização das técnicas de computação desplugada.

Santos, et al. (2016) afirma que com essas técnicas é possível estimular o raciocínio e o PC e, que além disso, contribui para a criação de ferramentas que possibilitem uma melhor resolução de problemas. Sendo assim, escolas que não possuem este recurso, também podem desenvolvê-lo a partir de atividades que irão refletir diretamente na maneira de resolver problemas.

A lógica de programação possibilita ao aluno aprimorar suas habilidades, ao estruturar um problema o indivíduo estará segmentando-o para resolvê-lo de forma simplória (BARBOSA, 2017).

Dessa forma, o indivíduo fica a par de conceitos que subsidiam a resolução de problemas e adquire habilidades para estabelecer variáveis, aplicar estrutura condicional de repetição e lógica de programação em que representam uma forma introdutória fundamental na estruturação de instruções para resolução de problemas, sendo estes conhecimentos essenciais para o desenvolvimento do PC (ZANETTI; OLIVEIRA, 2015).

Scolari (2007) coloca que inserir conceitos de Computação pode desenvolver o raciocínio lógico e matemático permitindo tornar os alunos mais críticos nas diferentes disciplinas, e Santos, et al. (2016) afirma ainda, que os indivíduos tendem a ser mais que apenas meros consumidores de tecnologias, mas sim, produtores.

O interesse em realizar este curso surgiu a partir de experiências tidas em trabalhos já realizados nesta área, tendo este, bons resultados, sendo apresentado em escolas e na semana tecnológica em praça pública.

\subsection{Metodologia de Execução}

O curso será ofertado a quinze (15) participantes, com faixa etária não determinada. Para os participantes, é necessário que possuam conhecimentos em Computação, noções de lógica de programação, algoritmos e/ou áreas afins. Sua duração será de 4 horas com os seguintes conteúdos programáticos:

Apresentação do PC; 
Apresentação das ferramentas;

Introdução a programação em blocos;

Desenvolvimento dos princípios do PC;

\subsubsection{Discriminação das fases do curso}

O curso de S4A será aplicado e distribuído nas seguintes fases:

$\mathbf{1}^{\circ}$ fase: apresentação do PC, da plataforma S4A e do Arduino. Esta fase será um momento dialogado por intermédio de recursos audiovisuais para exposição dos conceitos, relevância e princípios básicos do PC, que são: definição, organização, abstração e solução do problema.

$\mathbf{2}^{\mathbf{0}}$ fase: apresentação de mini-projetos utilizando a plataforma de programação em blocos S4A para facilitar o entendimento dos alunos sobre lógica de programação e explorar o funcionamento da plataforma de prototipagem Arduino no gerenciamento dos sensores/atuadores.

- Botão e LED: Um simples exemplo mostrando como acionar um LED apertando um botão.

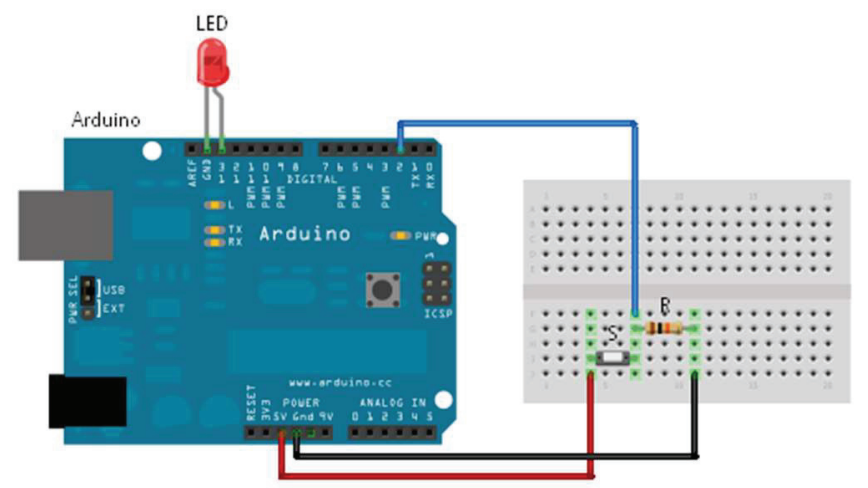

Figura 3: Modelagem da prototipação botão e LED. Fonte: S4A 2019.

- $\quad$ LED RGB: Utilizando um LED RGB.

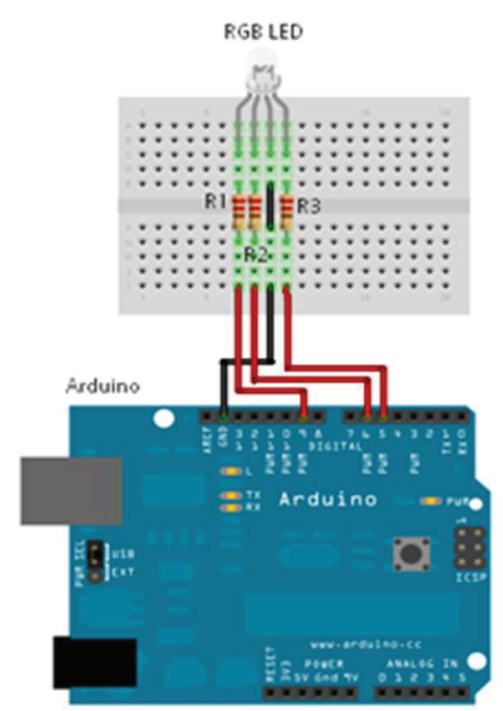

Figura 4: Modelagem da prototipação LED RBG. Fonte: S4A 2019. 
- Botão, LED e mantendo estado. Um LED que muda de estado quando aperta um botão.

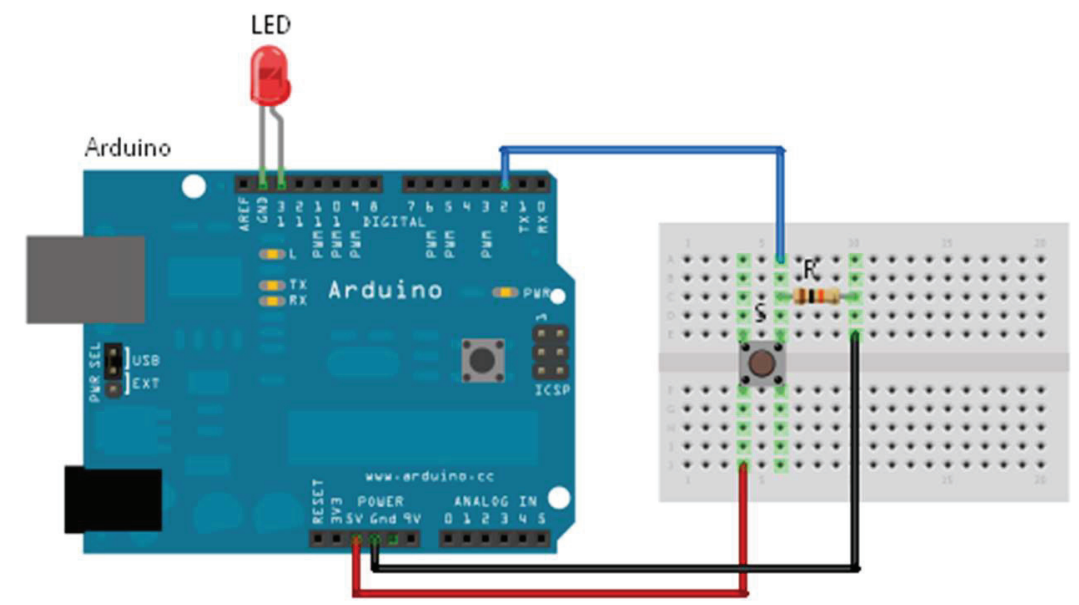

Figura 5: Modelagem da prototipação botão e LED. Fonte: S4A 2019.

- Fotoresistor e LED. Utilizando a entrada de um sensor fotoresistor para acionar um LED.

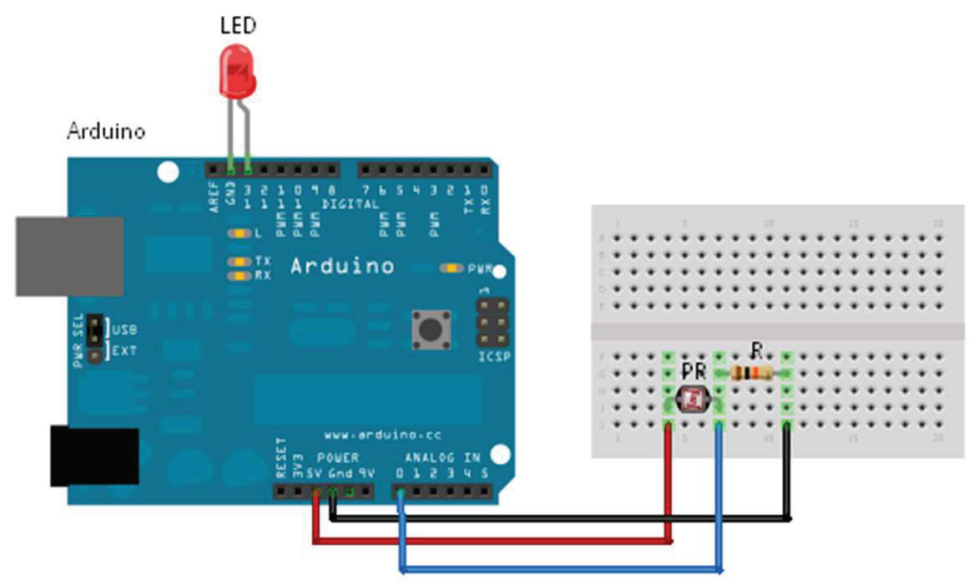

Figura 6: Modelagem da prototipação fotoresistor e LED. Fonte: S4A 2019.

$3^{\circ}$ fase: $\mathrm{O}$ modelo didático selecionado consiste em um protótipo para gerenciar o estacionamento. Será fragmentado em 4 partes e distribuídas em: (a) carro, (b) semáforo, (c) controle de acesso e (d) controle de vagas (figuras 7 e 8). Os participantes serão divididos em grupos.

Cada grupo ficará responsável pela construção de uma das partes destacadas anteriormente seguindo os princípios do PC que estão descritos abaixo: 
(I) definição: Segue-se o problema geral: Como seria possível minimizar a onerosidade de um estacionamento em pleno século XXI?

- Como guiar um carro por meio computacional?

- Como permitir um melhor fluxo no trânsito próximo ao estacionamento?

- Como controlar o acesso ao estacionamento de forma autônoma?

- Como fazer um controle de vagas indicando qual vaga está disponível?

(II) organização: Visualizar e delimitar a problemática de modo a saber quais recursos e tempo levará para desenvolvimento da solução.

(III) abstração: fragmentação de um problema maior em partes menores, permitindo assim, a definição de uma sequência de passos lógicos para se chegar a solução.

(IV) solução do problema: destacado nas figuras a seguir (figuras 7 e 8 ).
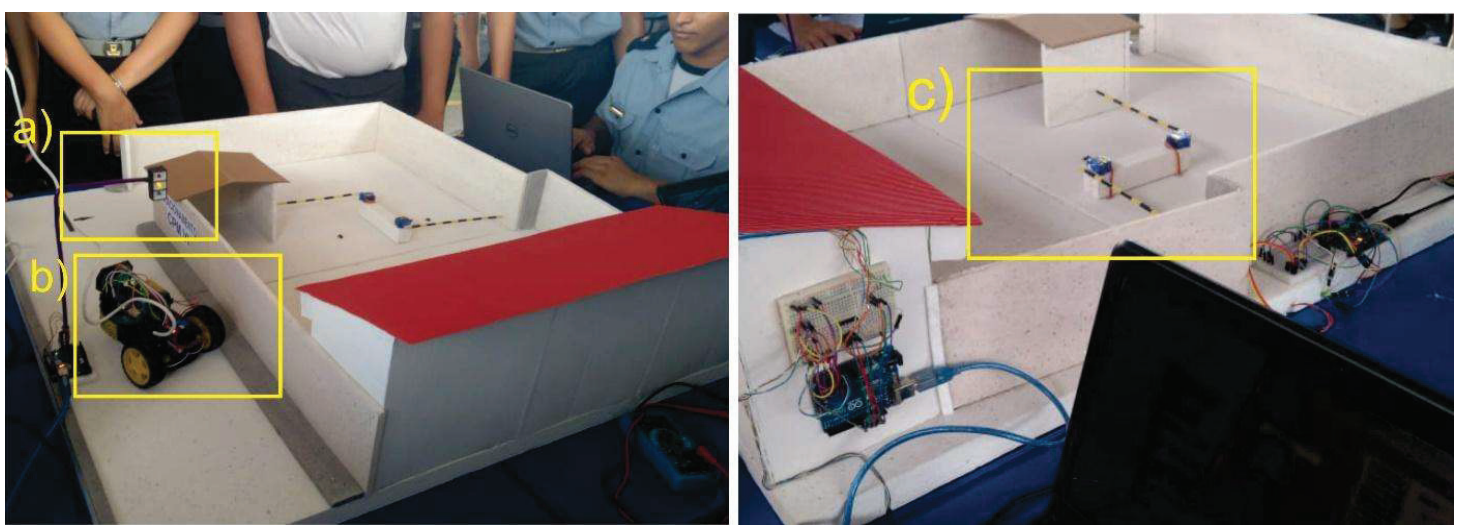

Figura 7: Apresentação dos protótipos em trabalhos passados.

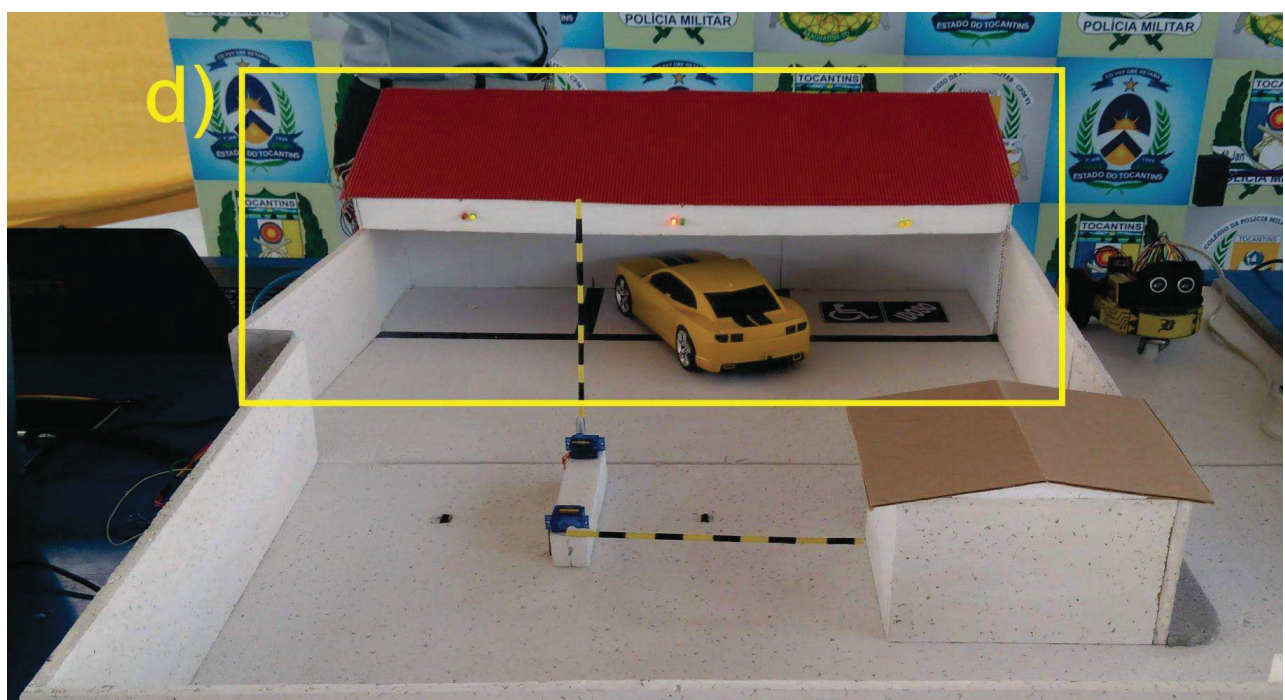

Figura 8: Apresentação dos protótipos em trabalhos passados. 
$4^{\mathbf{0}}$ fase: caracteriza-se pelo desenvolvimento do modelo didático com base no que foi definido na fase anterior. (a) carro, (b) semáforo, (c) controle de acesso e (d) controle de vagas. Os participantes deverão desenvolver a lógica de programação para o funcionamento do estacionamento automatizado, aplicando-se, o que foi apresentado no minicurso. Como foi dividido as partes precisarão fazer um trabalho colaborativo, proporcionando o conhecimento das partes aos colegas por meio da socialização e discussão do projeto.

A seguir, na figura 9 apresenta-se o código para condução do carro no estacionamento.
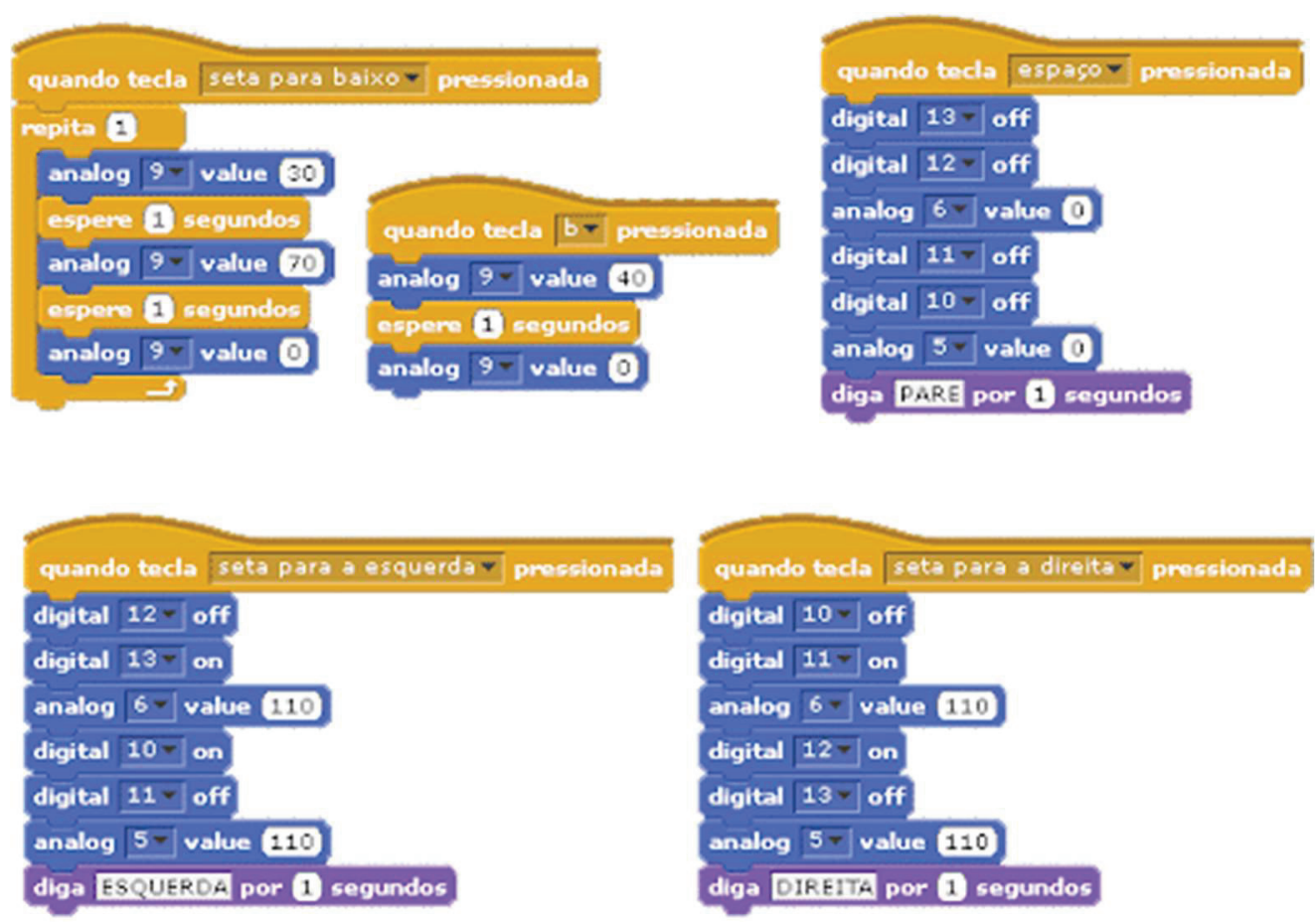

digital $11=$ on

analog $6=$ value 110

digital $12=$ on

digital $13=$ off

analog $5 \mathrm{r}$ value 110

diga DIREITA por 1 segundos
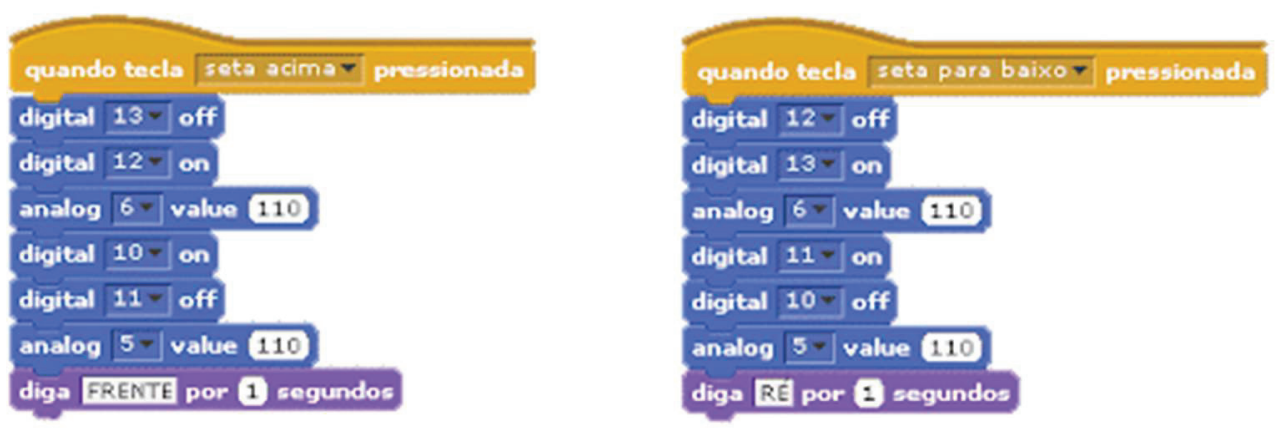

Figura 9: controle do carro.

Na figura 10 é apresentado o código para o semáforo. 

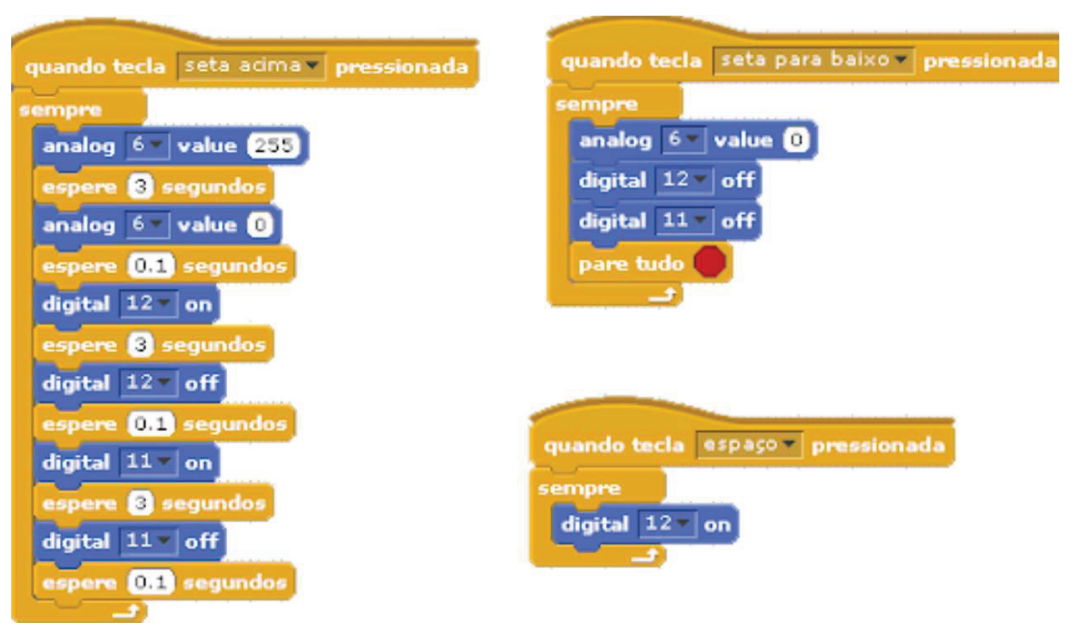

Figura 10: semáforo.

A figura 11 apresenta-se o código para o controle de acesso ao estacionamento
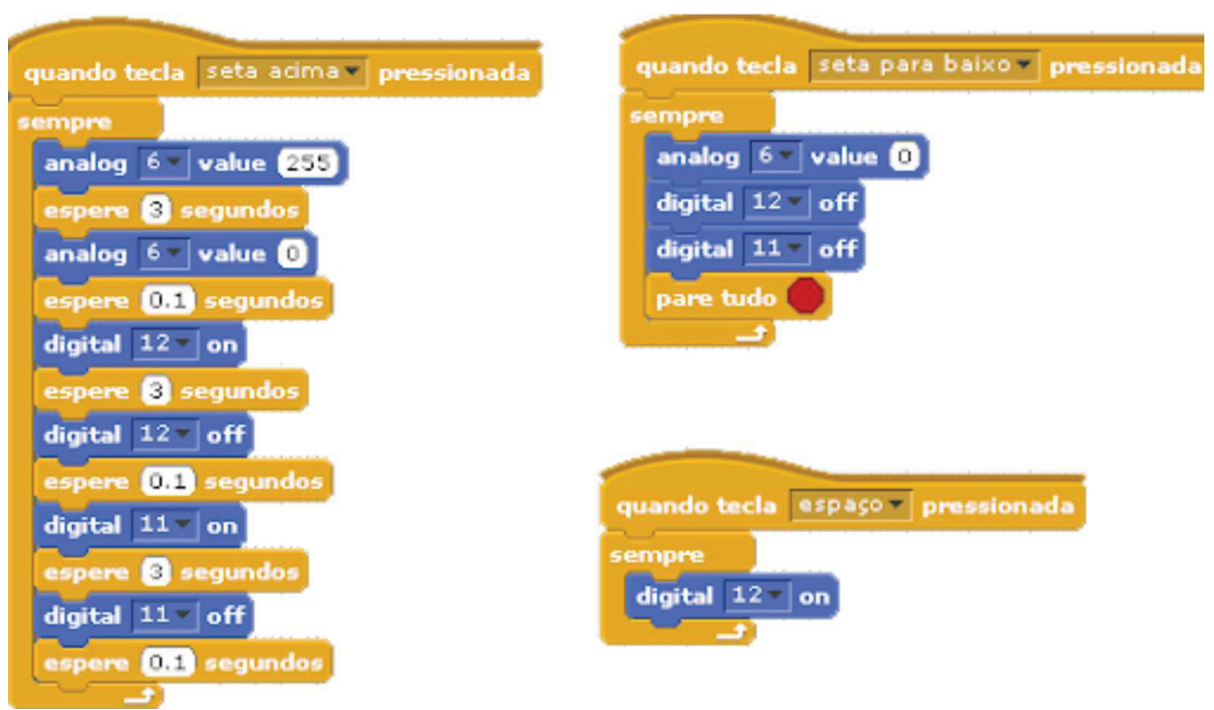

Figura 11: controle de acesso.

A figura 12 mostra o código para o controle das vagas no estacionamento. 


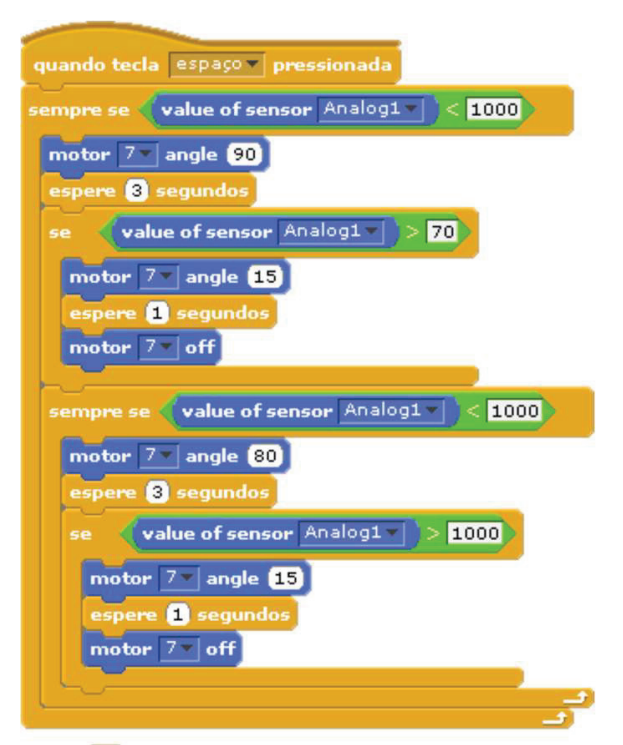

Figura 12: controle de vagas

\subsubsection{Especificações dos materiais}

Neste capítulo será tratado a fundamentação teórica que será utilizada no processo de desenvolvimento do minicurso a ser desenvolvido. Desta forma, faz-se necessário o estudo de alguns conceitos, como sensores e ferramentas, tais como Arduino uno, sensor LDR, LED, sensor ultrassônico, motores DC, ponte h, motores servos, sensores de linha.

\subsubsection{Arduino}

O Arduino é uma plataforma open source de prototipagem com hardware e software flexível. Vale ressaltar que o Arduino possui um código fonte aberto, dispõe um próprio ambiente de desenvolvimento que utiliza a linguagem $C$. É uma poderosa ferramenta podendo ser utilizada em inúmeros projetos e/ou diversas áreas, tal pelo motivo do seu custo ser bem baixo comparado com outras placas de prototipagem, atualmente uma unidade está custando no valor de 30,00 reais.

No minicurso, o Arduino uno r3 será utilizado em várias etapas, tais como, controle de vagas no estacionamento, controle de acesso de entrada e de saída. O r3 irá controlar motores servos que serão acionados por meio de sensor de presença e um simulador de semáforo, assim como o carrinho, que ao detectar algum objeto, automaticamente aciona o buzzer, fazendo um pequeno som.

Uma placa Arduino Uno conta com 01 microcontrolador ATmega328P (Fabricado pela empresa Atmel), 14 entradas e saídas digitais, 6 entradas analógicas, 1 oscilador de cristal de $16 \mathrm{MHz}$ e pinos de alimentação com 3,3 V 5 V Terra (GND). (DE LIMA, 2013, p.3). 


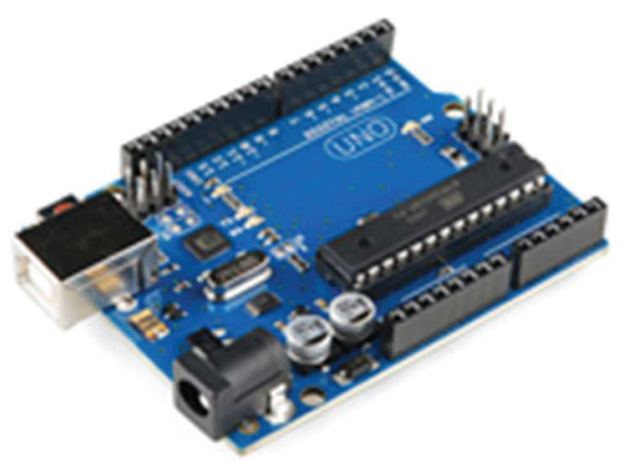

Figura 13: Arduino uno R3.

Fonte: arduoeletro 2019.

\subsubsection{Ultrassônico}

Ultrassônico é um sensor aplicado na área da robótica, utilizado para, por exemplo: desviar um robô de obstáculos e acionamento de alarmes. Este sensor pode ser controlado pela microcontroladora Arduino, Raspberry, etc. O ultrassônico faz leituras de 2 centímetros a 4 metros, com precisão de $3 \mathrm{~mm}$ de margens de erro. No minicurso, ele será utilizado no carrinho para desvio de obstáculo e seu custo é de $\mathrm{R} \$ 10,00$ a unidade.

O sensor ultrassônico é composto por um emissor e um receptor ultrassônico. $\mathrm{O}$ seu funcionamento acontece quando o emissor emite o sinal ultrassônico no momento em que encontra algum objeto e retorna esta informação ao sensor. Com base no tempo que o sinal ultrassônico emitido leva para retornar ao sensor, o mesmo já efetiva o cálculo da distância do sensor com o objeto (FELIPEFLOP, 2019).

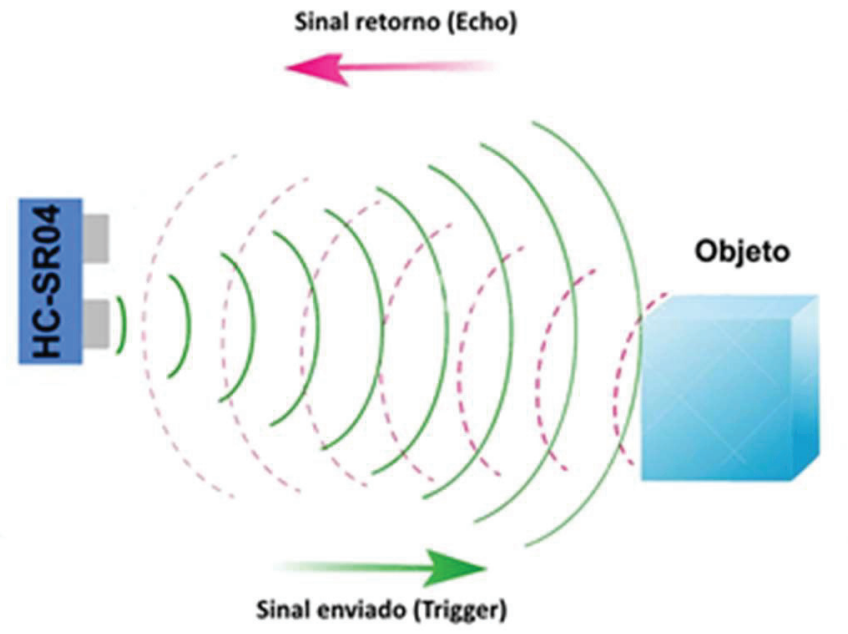

Figura 14: Sensor Ultrassônico.

Fonte: filipeflop 2019.

1.4.2.3. Led 
Led é um diodo de emissão de luz, caracterizado pelo componente que conduz corrente elétrica, que ao passar pelo seu cristal, caracterizam-se as cores vermelha, verde, amarelo, etc.

Este LED possui polaridades e deve ser ligado corretamente com seu terminal maior anodo sendo positivo e seu terminal menor catodo, sendo o negativo, como mostra na figura abaixo. Este diodo de emissão de luz será utilizado na vaga de estacionamento para informar se a vaga está livre ou não, no semáforo nas cores verde, amarelo e vermelho. Uma unidade custa em média R\$2,00 (FELIPEFLOP, 2019).

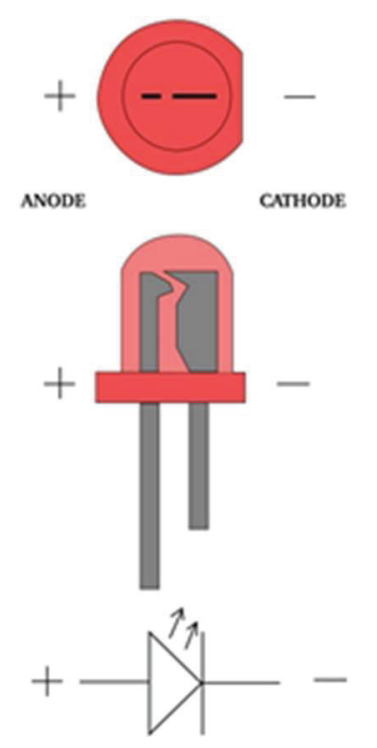

Figura 15: LED.

Fonte: filipeflop 2019.

\subsubsection{LDR}

O LDR é um resistor dependente de luz. Neste resistor, quanto maior a luminosidade, menor será sua resistência. O LDR não tem polaridade, isto é, pode ser ligado em positivo ou negativo e contém de um semicondutor de alta resistência. Para detectar mudanças, este resistor utiliza 10ms e seu custo equivale a menos de R \$1,00 (FELIPEFLOP, 2019).

No minicurso, o sensor LDR será utilizado no controle de vagas, para detectar quando um veículo estiver em uma determinada vaga, informando através de um LED diodo de emissão de luz, se a vaga está ocupada ou não. 

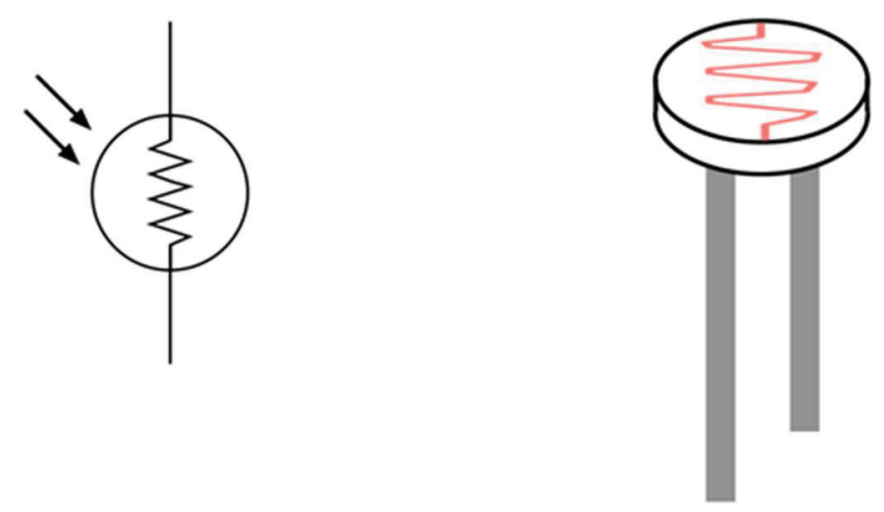

Figura 16: LDR.

Fonte: blogs.plymouth.ac.uk 2019.

\subsubsection{TCRT5000}

O sensor TCRT5000 conhecido como sensor de seguidor de linha, muito utilizado na área da robótica industrial e educacional, é composto de dois diodos de emissão de luz, sendo um emissor e outro receptor de sinal infravermelho. O seu funcionamento acontece quando o emissor emite luz infravermelho e, se este não retornar em intensidade suficiente, o mesmo tem seu funcionamento interrompido.

No minicurso, ele será utilizado no controle de acesso à garagem. Quando o veículo chegar próximo a cancela, o sensor TCRT5000 irá identificá-lo, enviando um sinal para Arduino, que irá acionar o motor servo para abertura do controle de acesso a garagem. Este sensor possui polaridades como mostra na figura abaixo, e seu custo é, em média R\$6,00 (FELIPEFLOP, 2019).

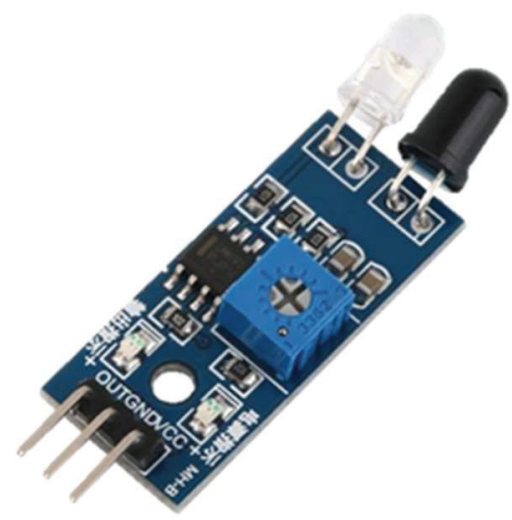

Figura 17: Sensor TCRT5000.

Fonte: Baú da eletrônica 2019.

\subsubsection{Rodas}


A roda boba, também conhecida como rodízio giratório de $30 \mathrm{~mm}$, será utilizada no minicurso descrito neste trabalho, especificamente no carrinho que é controlado pelo computador. Bem como esta roda boba, existe a roda de $68 \mathrm{~mm}$ de coloração amarela, também muito utilizada em projetos, como de carrinho autônomo e não autônomo. No minicurso será utilizado o carrinho, que será controlado pelo computador, como mostra na imagem abaixo, sendo do lado esquerdo a roda boba e do lado direito, a roda $68 \mathrm{~mm}$, cada uma com o mesmo valor de R\$6,00 (FELIPEFLOP, 2019).

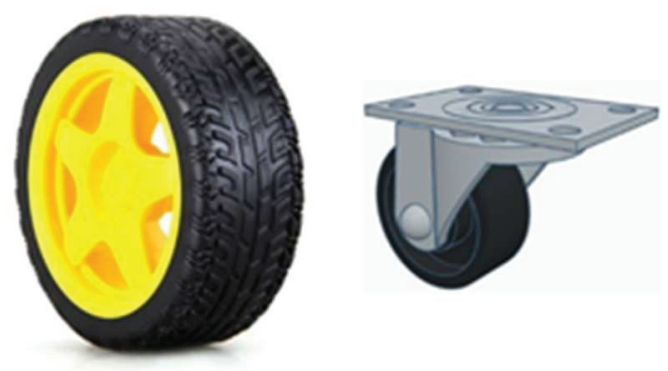

Figura 18: Roda Boba, Roda de $68 \mathrm{~mm}$. Fonte: Eletrogate 2019.

\subsubsection{Motor DC}

O Motor DC 6V é diferente de outros motores, tais como o motor de passo 6v, pois este possui uma caixa de redução e um eixo duplo, podendo ser utilizado nos dois lados. $\mathrm{O}$ motor DC 6V possui polaridades e quando ligado em polaridades diferentes, o mesmo muda a rotação de horário para anti-horário do motor.

A utilização do motor DC 6V é simples e facilita os projetos robóticos e/ou de engenharia, pelo seu baixo custo, equivalente a $R \$ 15,00$. Este motor será utilizado no carrinho que é controlado pelo computador, o mesmo, controlado pela ponte $\mathrm{h}$, como mostra na figura abaixo.

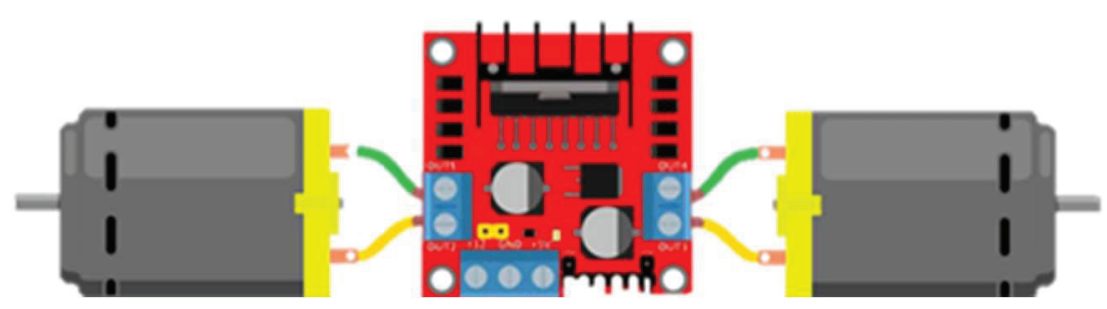

Figura 19: Motor DC 6V (Ponte h).

\subsubsection{Ponte H}


A ponte h é um circuito que controla a saída de corrente podendo inverter as polaridades, uma vez que, sendo alimentado inverta o sentido de funcionamento, como por exemplo: motor DC 6V são motores que pode ser ligado em ambas polaridades, ou seja quando a ponte $\mathrm{h}$ inverte a saída ele também irá inverter a sua rotação de horário para anti-horário (FELIPEFLOP, 2019). É de suma importância ressalta que o mesmo poder ser utilizado em projetos com válvula solenoide, rele, motor DC é motor de passo, como mostra a próxima figura.

No minicurso, a ponte h será utilizada no carrinho controlado pelo computador, o mesmo será utilizado para controlar a saída de corrente para os motores DC 6V com caixa de redução.

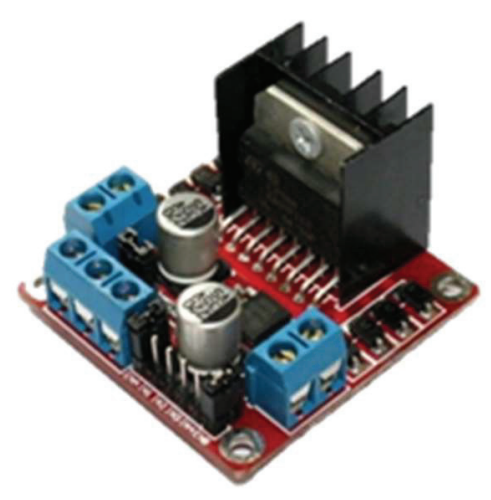

Figura 20: Ponte H. Fonte: Filipeflop.

\subsubsection{Servomotor}

Micro Servo 9g SG90 é um motor de fácil uso, pois o mesmo tem seu custo benefício barato, onde uma unidade custa em média, $R \$ 16,00$. Este micro faz um giro de até $160^{\circ}$ graus, possui polaridade e não pode ser ligado em polaridades diferentes (FELIPEFLOP, 2019). No minicurso, ele será utilizado no controle de acesso. Quando um veículo chegar próximo ao controle, o sensor óptico reflexivo irá identificá-lo e enviará a informação para o Arduino, que irá acionar os motores micro servo 9g SG90 como mostra na próxima figura.

De acordo com Almir (2013),

"Servomotor é uma máquina, mecânica ou eletromecânica, que apresenta movimento proporcional a um comando, em vez de girar ou se mover livremente sem um controle mais efetivo de posição como a maioria dos motores; servomotores são dispositivos de malha fechada, ou seja: recebem um sinal de controle; verificam a posição atual; atuam no sistema indo para a posição desejada." 


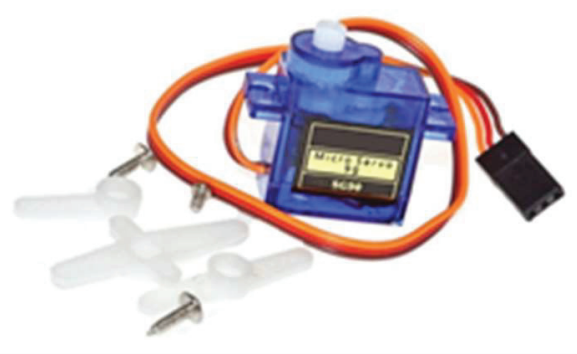

Figura 21: Micro Servo 9g SG90. Fonte Filipeflop 2016.

\subsection{Resultados Esperados}

Espera-se que a atividade promova entusiasmo nos participantes e possa contribuir para o desenvolvimento significativo de conceitos e habilidades de lógica de programação e Arduino, de forma a introduzi-los no PC com auxílio da robótica educacional permitindo maior concretude e autonomia no aprendizado dos alunos, preparando-os para os desafios de aprender e viver na sociedade atual.

Espera-se que o curso venha contribuir para uma aprendizagem significativa de conceitos, desenvolver habilidades de lógica de programação e manuseio da plataforma Arduino, embasando-se em alguns princípios do PC, gerando produtos para educação básica permitindo maior concretude e autonomia no aprendizado dos participantes, preparando-os para os desafios de aprender e viver na sociedade atual.

Que os participantes adquiriram habilidades como: manipular alguns sensores e atuadores (ultrassônico, infravermelho, luminosidade, LEDs, buzzers e motores), desenvolver conhecimentos básicos de eletrônica, compreender razoavelmente a lógica de programação no S4A e sua interação com hardware, consigam ser mais autônomos no desenvolvimento das atividades do seu cotidiano.

Sendo assim, capazes de analisar vários problemas do seu cotidiano, buscando possíveis soluções expressadas em modelos didáticos que sirvam tanto como produtos gerados para atender diversas áreas do conhecimento abordadas no ensino, quanto para modelos que influencie a criatividade na construção de outros modelos didáticos, gerando assim um processo de aprendizagem continuada.

\subsection{Agradecimentos}

Os agradecimentos aos professores Rogério Pereira de Sousa e Ramásio Ferreira de Melo, pelas contribuições e apoio para o desenvolvimento do minicurso Scratch For Arduino, primordial para o desenvolvimento deste trabalho. Ao Instituto Federal de Educação, Ciência e Tecnologia do Tocantins - Campus Araguatins, por proporcionar o desenvolvimento pessoal e profissional, por proporcionar a pesquisa, a extensão e o desenvolvimento do PC na Educação Básica.

\subsection{Referências}

ALBUQUERQUE, David et al. Uma Experiência do Uso Do Hardware Livre Arduino no Ensino De Programação De Computadores. In: Anais do Workshop de Informática 
$\begin{array}{lllll}\text { na } & \text { Escola. } & 2016 . & \text { p. } & 51 .\end{array}$ ie.org/pub/index.php/wie/article/download/6602/4513>. Acesso em: 29 maio 2019.

ALMIR.Como Funcionam os Servos Motores de Modelismo. O Mecatronico, 2013. Disponível em: <https://omecatronico.com.br/blog/como-funcionam-os-servosmotores-de-modelismo/>. Acesso em: 20 jul. 2019.

ARANTES, Flávia Linhalis; RIBEIRO, Paula Eduarda Justino. Desenvolvimento do PC com Valores da Ética Hacker. Informática na educação: teoria \& prática, v. 20, n. 2 mai/ago.

Disponível

em:

$<$ https://seer.ufrgs.br/InfEducTeoriaPratica/article/view/68953/43628>. Acesso em: 29 maio 2019.

ARDUINO. Disponível em: <www.arduino.cc/>. Acesso em: 27 jan. 2019.

BARBOSA, Débora Nice Ferrari et al. ENSINANDO LÓGICA COM AS TECNOLOGIAS DA INFORMAÇÃO: DESENVOLVENDO O RACIOCÍNIO LÓGICO E O PENSAMENTO COMPUTACIONAL. CATAVENTOS-Revista de Extensão da Universidade de Cruz Alta, v. 9, n. 1, p. 54-72, 2017. Disponível em: $<$ http://www.revistaeletronica.unicruz.edu.br/index.php/Cataventos/article/download /5334/1127>. Acesso em: 27 maio 2019.

BRASIL. Ministério da educação. Conselho Nacional de Educação. Parecer CNE/CES 136/2012, 2012. Disponível em: $<$ http://portal.mec.gov.br/index.php?option $=$ com_docman\&view $=$ download\&alias $=1$ 1205-pces136-11-pdf\&category_slug=julho-2012-pdf\&Itemid=30192>. Acesso em: 28 jul. 2019.

DE LIMA, Gustavo Fernandes; Glauco George C.; SALAZAR, Andrés Ortiz. CONTROLE DE TEMPERATURA DE UMA TOCHA DE PLASMA TÉRMICO COM ACOPLAMENTO INDUTIVO UTILIZANDO A PLACA ARDUINO. 2013. Disponível em: < http://www.sbai2013.ufc.br/pdfs/5130.pdf $>$. Acesso em: 24 jun. 2019.

CUNY, J.; SNYDER, L.; WING, Jeannette M. Demystifying computational thinking for non-computer scientists. Unpublished manuscript in progress, 2010. Disponível em: $<$ http://www.cs.cmu.edu/ CompThink/resources/TheLinkWing.pdf $>$. Acesso em: 20 maio 2019.

FRANÇA, Rozelma Soares de; AMARAL, Haroldo José Costa do. Proposta metodológica de ensino e avaliação para o desenvolvimento do PC com o uso do scratch. In: Anais do Workshop de Informática na Escola. 2013. p.179. Disponível em: <http://www.br-ie.org/pub/index.php/wie/article/download/2646/2300>. Acesso em: 30 maio 2019.

KALIL, Fahad. et al. Promovendo a robótica educacional para estudantes do ensino médio público do Brasil. Nuevas Ideas en Informática Educativa, TISE, p. 739-742, 2013. Disponível em: < http://www.tise.cl/volumen9/TISE2013/739-742.pdf $>$. Acesso em: 22 maio 2019.

PAPERT, Seymour. Mindstorms: Children, computers, and powerful ideas. Basic Books, Inc., 1980. 
PEREIRA, Amanda C.; FRANCO, Matheus E. Desenvolvendo o pensamento computacional no ensino fundamental com Arduino e Scratch. In: $5^{\circ}$ Encontro Nacional de Computação dos Institutos Federais (ENCompIF 2018). SBC, 2018. Disponível em: $<$ https://sol.sbc.org.br/index.php/encompif/article/view/3561> Acesso em: 15 jun. 2019.

RAMOS, Fellipe; TEIXEIRA, Lilian da Silva. Significação da aprendizagem através do PC no ensino médio: uma experiência com scratch. In: Anais do Workshop de Informática na Escola. 2015. p. 217. Disponível em: $<$ http://www.brie.org/pub/index.php/wie/article/download/5024/3434>. Acesso em: 12 maio 2019.

RODRIGUEZ, Carla et al. PC: transformando ideias em jogos digitais usando o Scratch. Anais do Workshop de Informática na Escola. 2015. p. 62. Disponível em: $<$ http://brie.org/pub/index.php/wie/article/view/4992>. Acesso em: 30 maio 2019.

S4A. Disponível em: <http://s4a.cat/>. Acesso em: 21 maio. 2019.

FELIPEFLOP. Disponível em: $<$ https://www.filipeflop.com/>.Acesso em: 24 ago. 2019.

SANTOS, Elisângela Ribas dos et al. Estímulo ao PC a partir da Computação Desplugada: uma proposta para Educação Infantil. 2016. Disponível em: $<$ http://dehesa.unex.es/handle/10662/5939>. Acesso em: 28 maio 2019.

SCAICO, Pasqueline Dantas et al. Ensino de programação no ensino médio: Uma abordagem orientada ao design com a linguagem scratch. Revista Brasileira de Informática na Educação, v. 21, n. 02, p. 92, 2013. Disponível em: $<$ http://www.academia.edu/download/43035180/2364-4111-1-PB.pdf $>$. Acesso em: 28 maio 2019.

SCOLARI, T. Angélica; BERNARDI, Giliane; CORDENONSI, Z. Andre. O Desenvolvimento do Raciocínio Lógico através de Objetos de Aprendizagem. Santa Maria-RS, $2007 . \quad$ Disponível em: $<$ http://www.cinted.ufrgs.br/ciclo10/artigos/4eGiliane.pdf $>$. Acesso em: 28 maio 2019.

SOBREIRA, Elaine Silva Rocha; TAKINAMI, Olga Kikue; DOS SANTOS, Verônica Gomes. Programando, Criando e Inovando com o Scratch: em busca da formação do cidadão do século XXI. Jornada de Atualização em Informática na Educação, v. 1, n. 1, 2013. Disponível em: <https://br-ie.org/pub/index.php/pie/article/view/2592/2248> Acesso em: 28 maio 2019.

VALENTE, José Armando. Integração do PC no currículo a Educação Básica: diferentes estratégias usadas e questões de formação de professores e avaliação do aluno. Revista e-Curriculum, v. 14, n. 3, p. 864-897, 2016. Disponível em: $<$ http://www.redalyc.org/pdf/766/76647706006.pdf>. Acesso em: 23 maio 2019.

WING, Jeannette M. Computational thinking. Communications of the ACM, v. 49, n. 3. p. 33-35, 2006. Disponível em: <https://www.cs.cmu.edu/ 15110-s13/Wing06ct.pdf>. Acesso em: 28 maio. 2019.

ZANETTI, Humberto; OLIVEIRA, Claudio. Práticas de ensino de Programação de Computadores com Robótica Pedagógica e aplicação de Pensamento Computacional. In: Anais dos Workshops do Congresso Brasileiro de Informática na Educação. 2015. 
p. $\quad 1236$.

Disponível

em:

$<\mathrm{https}: / /$ br-

ie.org/pub/index.php/wcbie/article/view/6268/4389>. Acesso em: 19 jul. 2019. 